\title{
COMPLEX COMPARATIVE TESTS ON HISTORIC STONE
}

\author{
Milož Drdáckž*, Hana Hasníková, Jaroslav Valach \\ Institute of Theoretical and Applied Mechanics of the Academy of Sciences of the Czech Republic, Prosecká 76, \\ 19000 Praha, Czech Republic
}

KEY WORDS: Stone mechanical characteristics, Physical characteristics, Lithotype, Water absorption, Micro drilling, Peeling test, Ultrasonics

\begin{abstract}
:
This paper presents an abbreviated review of the potential capacities of the project on Non-destructive and Considerately (Medium) Destructive Methods for Testing Historic Stone, developed within the $7^{\text {th }}$ EC FP STONECORE project. These methods include ultrasonic tests, peeling tests, drilling resistance and water uptake by various approaches. The material characteristics acquired by means of these methods are compared with the characteristics measured by destructive standard tests, and the observed correlations are discussed.
\end{abstract}

\section{INTRODUCTION}

Within the STONECORE [1] project, supported under the 7th EC Framework Programme, several innovative techniques for investigating some characteristics of stone have been suggested and developed. This paper presents a brief comparison between the potential capacities of the non-destructive and considerately (medium) destructive diagnostic methods that have been developed, on the one hand, and standard testing methods, on the other. It should be pointed out that destructive tests for determining mechanical characteristics are used for calibrating and assessing non-destructive methods.

In the course of research work within the STONECORE project, some further techniques were tested, e.g. hardness measurements by means of sphere indentation, rebound hammer tests, sequential picture evaluation and ultrasound measurements in a depth profile. However, the sampling was limited and/or the results were not convincing enough to develop the methods more deeply, so they are not included in this report. The characteristics exhibited by some of the tested stones were quite significantly heterogeneous. This must be taken into account when the results of the correlation studies are examined.

\section{TESTED MATERIALS AND TEST SPECIMENS}

The comparative tests were carried out on rocks that were available in necessary quantities, and that were related to historic buildings. Studies were carried out on stone blocks taken from Charles Bridge in Prague and from the Church of St. Barbara in Kutná Hora during recent repairs.

The tests included the following materials: "opuka" marl stone sound stone from a quarry; travertine limestone - sound stone from a quarry; quartz sandstone - sound stone from a quarry in the Hožice region; arkose (sandstone) - stone from Charles Bridge; detrital limestone - stone extracted from the Church of St. Barbara in Kutná Hora; Nehvizdy sandstone - stone from Charles Bridge; and Petžín sandstone - stone from Charles Bridge.
The initial shape and size of the test specimens was chosen in the form of beams according to the standard specifications for tests of mechanical characteristics. The basic specimen dimensions were therefore $50 \mathrm{~mm} \mathrm{ž} 50 \mathrm{~mm} \mathrm{ž} 300 \mathrm{~mm}$. The dimensions of the specimens of Kutná Hora limestone were 50 $\mathrm{mm} \check{z} 33 \mathrm{~mm}$ ž $200 \mathrm{~mm}$, as only shorter beams were available there, and the cross section height-to-span ratio required for the bending tests was maintained. Five specimens (in exceptional cases three specimens) were prepared for each test.

\section{TESTED CHARACTERISTICS AND TEST CONDITIONS}

The destructive tests included determining the mechanical characteristics, namely strength in compression, strength in three-point bending (modulus of rupture), and the Young modulus of elasticity computed from the deflections measured during the bending tests. These tests require a sufficient volume of material to be extracted from existing buildings for preparing standard test specimens, and the tests are carried out in a laboratory.

Considerate destructive tests are intended for tests carried out in situ. They damage existing structures in a negligible manner from the aesthetic and also the static point of view. In this study tests of this kind were of drilling resistance, mercury porosimetry and microscopy on thin sections.

Other characteristics were measured using non-destructive methods, but for the sake of comparison some of them were applied in a way that cannot be used in situ. Thus the tests have some destructive features. Capillary water uptake and also ultrasonic measurements in the transition mode belong to the family of destructive tests, in terms of specimen preparation and application.

The only purely non-destructive tests here involve water absorption determined by means of the so-called Karsten tube and by new microtube measurements.

The test specimens were conditioned before the test in a climatic chamber (for standard tests in "dry conditions") at $70^{\circ} \mathrm{C}$ $\pm 5^{\circ} \mathrm{C}$ till an equilibrium state of moisture content, which was

Corresponding author. 
measured by weighing at intervals of $24 \pm 2$ hours with accuracy of $0,1 \mathrm{~g}$. In the equilibrium state the mass of the test specimen does not change by more than $0,1 \%$. After drying and before testing, the test specimens are stored in an environment with a temperature of $20^{\circ} \mathrm{C} \pm 5{ }^{\circ} \mathrm{C}$ until the temperature is balanced. The test was then carried out within 24 hours.

Two physical states were applied for the tests - dry conditions (as described above) and fully water-saturated conditions ( $\breve{C} S N$ 72 1154), in situations that were relevant for studying the characteristics of the materials (mechanical tests and ultrasonic tests). All the tests were carried out in the ITAM laboratories.

Petrography analysis (not described in the paper) followed the standard methodology (EN 12407) and local petrography tables were used. The structure of the samples and their mineralogical and petrographic composition were investigated in polarized microscopy (PPL in transmission polarized light, XPL for crossed prisms, RPL in reflected skew polarized light). Investigations of the basic matrix and cements in sandstone samples made use of SME and a CAMECA SX-100 microanalyser equipped with four crystal spectrometers (elements can be determined in the range from $\mathrm{B}$ to $\mathrm{U}$ ), and with detectors of secondary and reflected (backscattered) electrons (BSE).

\section{TESTING METHODS}

The testing methods are briefly characterized, without details of the measured data that is used for comparison or for correlation studies, as described below.

\subsection{Ultrasonic material characteristics}

Ultrasonic tests were carried out on beams with dimensions of 50 ž 50 ž $300 \mathrm{~mm}$ using the UKS 12 device produced by Geotron Elektronik. UKS 12 comprises a generator of electric impulses, two transducers (one for transmission and one for receiving) and a microsecond timer. The timer has a screen where the received wave is shown, so that the time when the wave passes through the sample can be read. The frequency used for the measurements was $20 \mathrm{kHz}$, and the data was measured in the three main mutually perpendicular directions typical for layered stone, Figure 1.

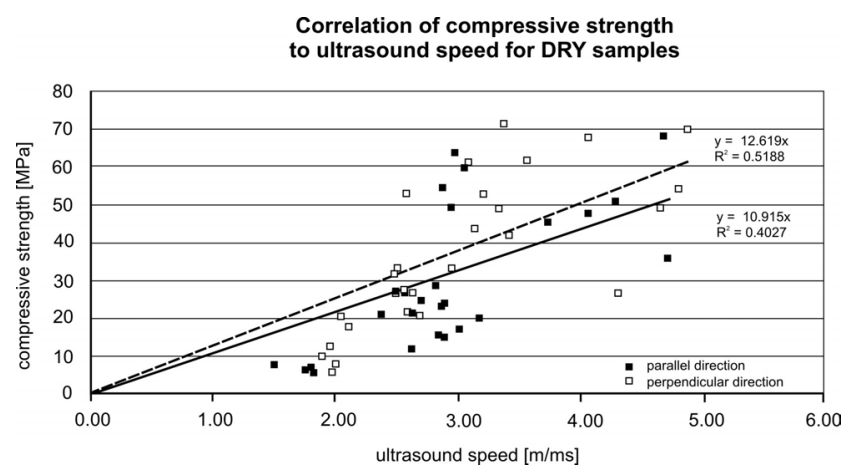

Figure 1. Correlation of compressive strength to ultrasound speed for dry samples.

\subsection{Near surface cohesion characteristics of stone}

A peeling test is used to determine the surface cohesion ("strength") of the material. It can be used for assessing surface degradation and/or for assessing improvements in surface properties after application of a consolidation agent. In the course of the test, adhesive strips are attached sequentially and then removed from the same place, and the weight of the removed material is determined by laboratory scales. The process model anticipates that some asymptotic value of the removed material will be reached by the end of the test (and denoted as A [g]). This value characterizes the surface strength, and should be related to the overall strength of the material, Figure 2.

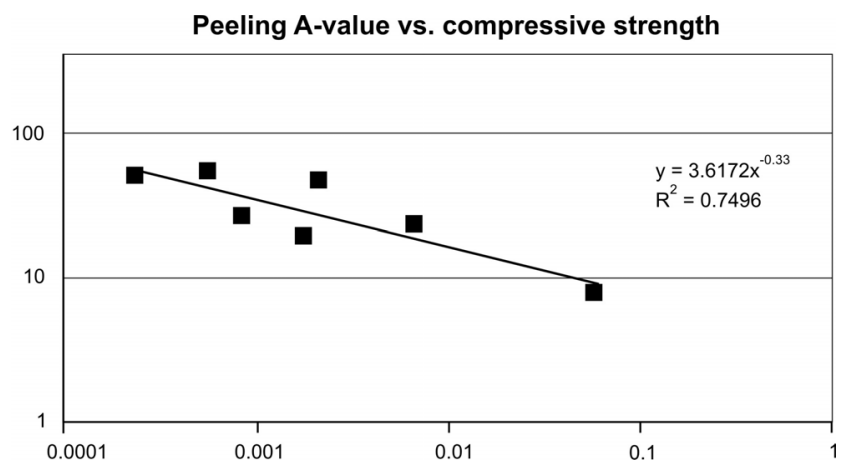

Figure 2. Correlation between the A-value [g] and the strength $[\mathrm{MPa}]$ of the tested material, showing indirect proportionality between the two properties.

The values of A should be indirectly proportional to the strength of the material. Lack of this correlation can be due attributed to several other factors, especially the fact that the material property called fracture toughness also comes into play. In relation to fracture toughness, the importance of the heterogeneity, porosity and strength of the interfaces between phases rises. The measurement procedure and a discussion of the influences on the measurement are presented in detail in (Drdáckž et al. 2012b).

An approximation form

$\mathrm{m}(\mathrm{n})=\mathrm{A}+\mathrm{B} * \mathrm{e}^{-\mathrm{C}^{*} \mathrm{n}}$

describing the sequence of weights of the removed material $\mathrm{m}(\mathrm{n})$ is also suggested in (Drdáckž et al. 2012b).

\subsection{Drilling resistance characteristics}

Drilling resistance is usually expressed in terms of the time it takes the drill to penetrate to a certain depth at a defined pressure and speed of revolution. However, on the basis of empirical observations, it can be related to strength and hardness. Drilling resistance is usually used for making a comparison between the state of the material before and after an intervention, or the effectiveness of various treatments is compared by drilling under the same conditions. Drilling resistance is expressed e.g. in seconds per millimeter.

Drilling resistance depends on two process parameters: velocity, taken as the number of revolutions per unit time, and applied force, which determines the rate at which the drill penetrates the material. This means that the rate varies from material to material, reflecting the strength profile of the specimen. This is the approach embodied in the Tersis device, manufactured by Geotron Elektronik.

Due to its constant load, the Tersis drilling device is best suited for investigating the strength profiles of weak and soft materials, sensitively recording every detail, every minute obstruction in the path of the drill. Accordingly, high frequency 
of data acquisition is obtained: about 30 records per second, corresponding to approximately one hundred records per millimeter, based on the typical drilling speed and several thousand data points, assuming a typical hole depth of about three centimeters. However, the results have to be interpreted carefully, distinguishing different phases of the material influencing the drilling speed. In addition, drilling resistance does not yield any results above a certain strength of the tested material.

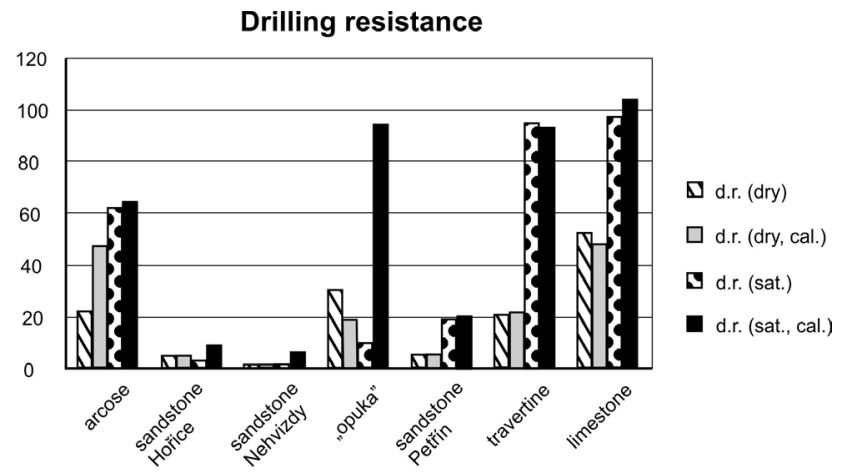

Figure 3. Summarized drilling resistance rates for the studied stones in dry and saturated condition.

The results presented in Figure 3 indicate strong influence of water on the drilling process, slowing down the process of removing the drilled material. Drill bits are worn away in the process of measuring drilling resistance. This causes an apparent change in the drilling resistance rate that has to be adjusted by calibration.

\subsection{Water absorption characteristics}

Three different methods have been used for determining water absorption. First, the absorption property was tested on beams $50 \check{z} 50 \check{z} 300 \mathrm{~mm}$, and also on cubes 50 ž 50 ž $50 \mathrm{~mm}$ for all the materials. All the tests kept to the conditions set by Czech technical standard žSN EN 1925: Natural stone test methods Determination of water absorption coefficient by capillarity (a Czech version of European Standard EN 1925:1999).

The so-called Karsten tube has been used for several recent decades for in situ measurements, e.g. (Rapp et al. 1997). It was the second method for water absorption measurements. However, the application of this method in situ leads to some difficulties, which can be summarized as follows: i) problems with fixing a heavy glass tube on to vertical surfaces, ii) problems with sealing the contact ring area, iii) the need for two operators - one who observes the water movement in the measurement tube with a stop-watch, and another who records the readings, iv) soiling of the surface with sealing putty.

A pilot prototype of an innovated device was therefore developed within the project, and it is being further improved. The new system is based on a way of making continuous electronic measurements of water infusion into the surface. This enables long-term recording of the water sorption from the very beginning. The device consists of a scaled glass microtube in which the movement of the meniscus is watched, and crossing of the marks is recorded manually by a switch or in a container with a float connected to a movement sensor for automatic reading. The measurement reduces the number of operators, it is more precise, more effective and faster (Drdáckž et al. 2011, Drdáckž et al. 2012a). The device is presented in Figure 4, and the correlation of all three methods is shown in Figure 5.

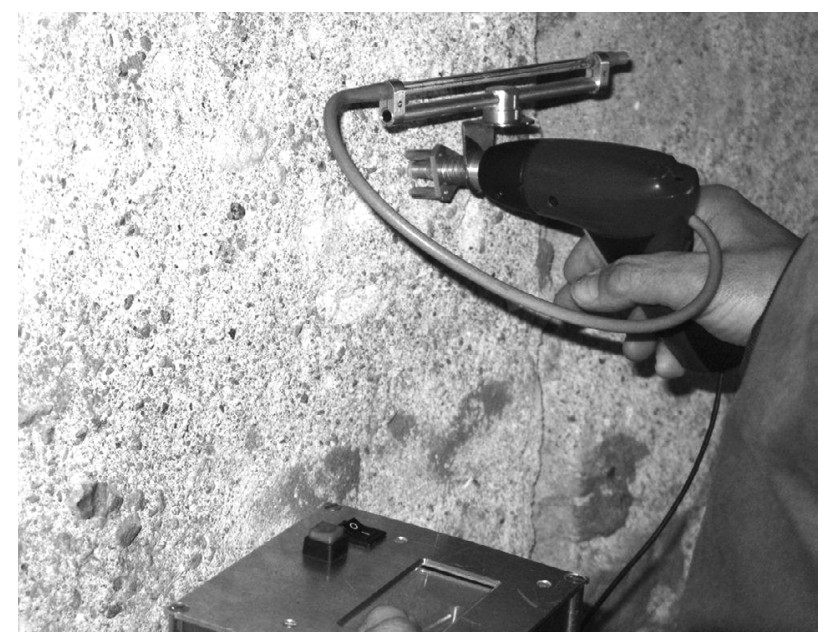

Figure 4. Application of a microtube device for in situ measurement of mortar water absorption characteristics.

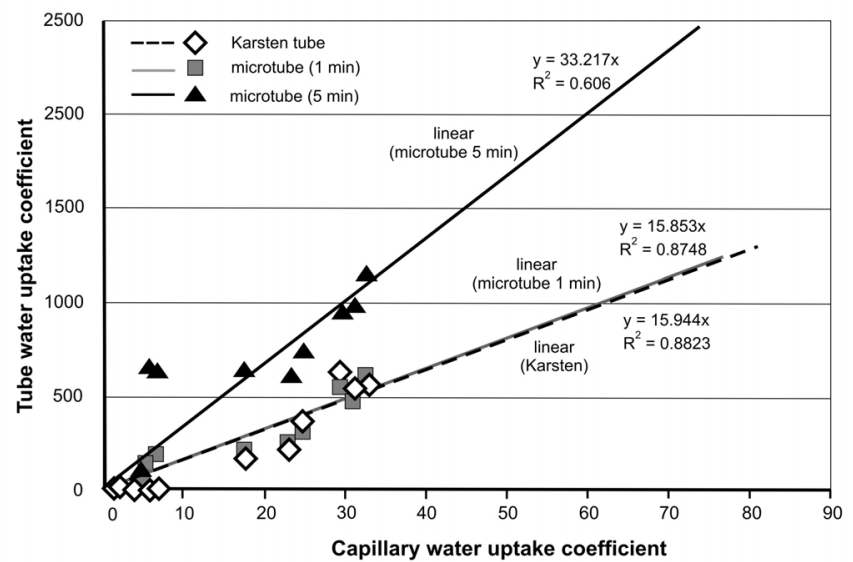

Figure 5. A comparison of water absorption characteristics measured by means of different methods.

\section{SPECIFIC MASS AND POROSITY CHARACTERISTICS}

Specific mass and also total and open porosity were determined on dry specimens after mechanical tests and/or on specimens intended for water-saturated mechanical tests before the destructive tests, according to the EN 1936 standard.

Mercury porosimetry was used for determining the porosity and the pore size distribution, i.e. the volumetric distribution of the open pores, which is assumed to have a circular cross section, according to their size (radius or diameter).

The stones under study are composed of elements of different atomic weight, but grouped into compounds, crystals and minerals of very similar density. Porosity is therefore a decisive factor determining the specific mass property. Due to this correlation, porosity can be assessed by specific mass measurement, see Figure 6. 


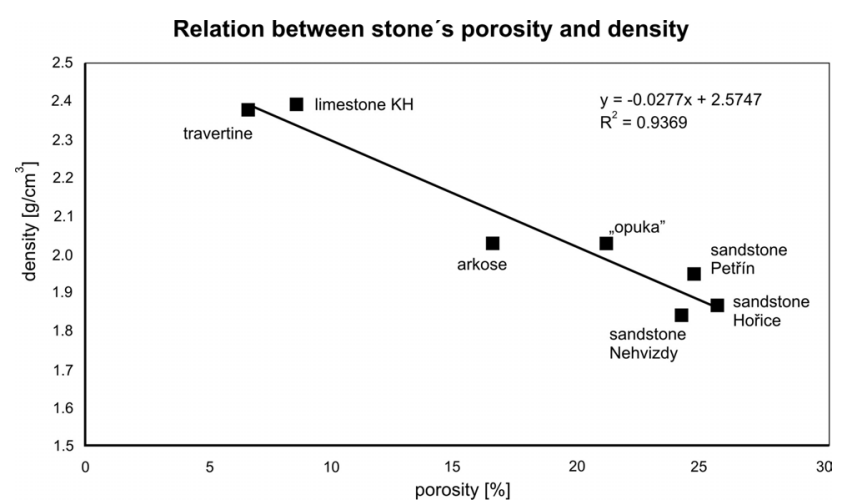

Figure 6. Relation between the porosity of the stone and its density.

\section{TESTS OF MECHANICAL CHARACTERISTICS}

Flexural strength in three-point bending was tested on beams 50 ž 50 ž $300 \mathrm{~mm}$. All the tests kept to the conditions set by the Czech technical standard žSN EN 12372: Natural stone test methods - Determination of flexural strength under concentrated load (a Czech version of European Standard EN 12372:2006).

Compression strength was tested on cubes 50 ž 50 ž $50 \mathrm{~mm}$. The tested samples were sawn from undamaged parts of beams formerly used for flexural strength. All the tests kept to the conditions set by Czech technical standard žSN EN 1926: Natural stone test methods - Determination of uniaxial compressive strength (a Czech version of European Standard EN 1926:2006).

Ten samples were tested for almost all of the stone materials and for each condition (dry, water-saturated), so the sets of results for statistical evaluation were relatively broad. Variation is a measure of the dispersion of the probability distribution, and can be taken as an indicator of the accuracy of the experiments. The accuracy for sets where the variation was below 0.20 was declared sufficient, and the final average value and standard deviation were calculated from the whole set. For sets where the variation exceeded 0.20 , values outside an interval of one standard deviation were eliminated from the final statistical evaluation. In a few cases, the final variation exceeds 0.20 , because further reduction of the value sets does not affect the results significantly. The acquired data was used for comparison or in correlation studies.

\section{CONCLUSION - COMPARISON OF THE TESTED METHODS}

The correlations between various characteristics not only provide information on the applicability of individual nondestructive methods but also indicate more profound dependencies and material qualities.

Naturally, the material density and the mechanical characteristics correlate. Because there is a fairly good correlation between porosity and bulk density, see Figure 6, a good correlation between porosity and mechanical characteristics is also expected, as confirmed in Figure 7. A relation between porosity and flexural strength is also a well documented fact.

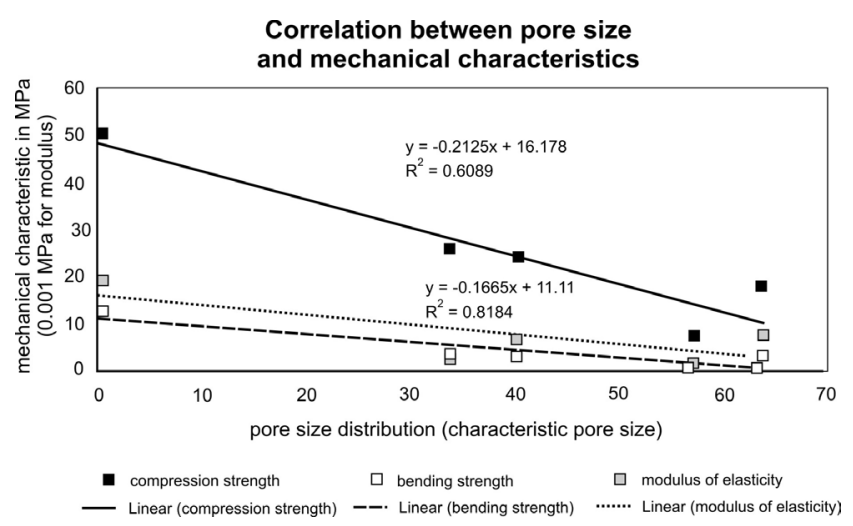

Figure 7. Correlation between pore size and mechanical properties.

In situ pore size measurement relies on the application of water uptake investigations. Our experiments proved, using various techniques, that there is a fairly good correlation between pore size characteristics and water absorption measurements, see Figure 8.

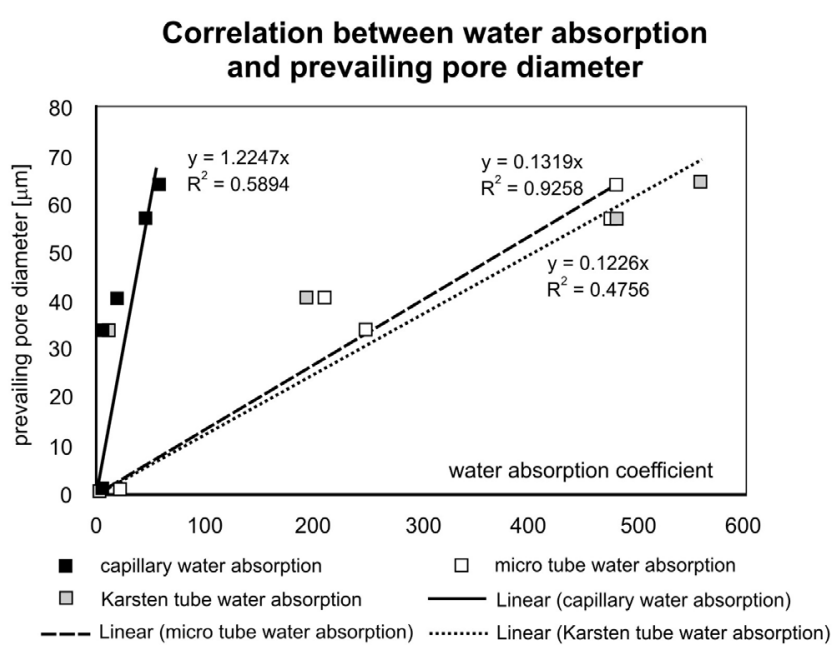

Figure 8. Correlation between water absorption, measured by means of various techniques, and the prevailing pore diameter.

Naturally, this also implies that mechanical characteristics can also be estimated via water uptake measurements. However, in practical situations the natural moisture content would make the method very difficult to apply, or it would be necessary to use special drying procedures and microtube measurements of the water uptake. For reasons of space, it is not possible to present the acquired data in greater detail and under various moisture conditions, which are very important in engineering practice.

The ability to assess values for the mechanical properties of stone that would otherwise be impossible to measure nondestructively is the main contribution of the comparative studies presented here.

The correlations presented here show that the development of new testing approaches for historic materials, namely when applied on site, has a significant potential and requires further research. The results achieved during the STONECORE project and our follow-up work indicate promising directions that are worth investigating and developing. 


\section{ACKNOWLEDGEMENTS}

The authors acknowledge kind support from the EC 7th FP STONECORE project, (STONECORE, Contract No. NMP2SE-2008-213651, Project Title: Stone Conservation for Refurbishment of Buildings, Co-ordinator: Prof. Dr. rer. nat. habil. Gerald Ziegenbalg, IBZ-Salzchemie GmbH\&Co, Halsbrücke, Germany), and from the Czech Science Foundation Project GAžR P105/12/G059. The authors also thank Dr. Zuzana Slížková for her consultations, and Jan Bryscejn, Jan Kolež, Ondžej Vála and Pavel Zíma for their careful work during the experiments.

\section{REFERENCES AND BIBLIOGRAPHY}

EC FP7 STONECORE NMP SME Collaborative Project No.213651, http://www.stonecore-europe.eu/index.php

Drdáckž, M., žernž, M., Slížková, Z., Zíma, P. 2011. Microtube device for innovative water uptake measurements, M.Krüger (Ed.): Cultural Heritage Preservation Proceedings of the European Workshop, Berlin, 26-28 September 2011, ISBN 9783-8167-8560-6, Fraunhofer IRB Verlag, Stuttgart, pp. 126-130

Drdáckž, M., Hasníková, H., Zíma,P. 2012a. Innovated water uptake measurements on historic stone surfaces. Deterioration and Conservation of Stone Proceedings of the 12th International Congress 22-26 October 2012, Columbia University, New York, (in print)

Drdáckž, M., Lesák, J., Rescic, S., Slížková, Z., Tiano, P., Valach, J. 2012b. Standardization of peeling tests for assessing the cohesion and consolidation characteristics of historic stone surfaces. Materials and Structures, 45, (4), pp. 505-520

Rapp, K., Wendler, E., Snethlage, R. 1997. Zerstörungsfreie Messung der Wasseraufnahme - Verbessertes Auswerteverfahren für die Messmethode nach Karsten. Berichte der Deutschen Mineralogischen Gesellschaft, Beih. z. Eur. J. Mineral, 9, (1), p. 288 
